\title{
HIV/AIDS-Related Knowledge among Persons with Physical Disability in Cameroon: A Qualitative Study
}

\author{
Tarkang $\mathrm{EE}^{* 1,2}$, Gbogbo $\mathrm{S}^{1}$ and Lutala $\mathrm{PM}^{3}$
}

${ }^{1}$ Department of Population and Behavioural Science, School of Public Health, University of Health and Allied Sciences, PMB 31, Ho, Volta Region, Ghana

${ }^{2}$ HIV/AIDS Prevention Research Network, Cameroon (HIVPREC), PO Box 36 Kumba, Southwest Region Cameroon ${ }^{3}$ School of Public Health \& Family Medicine, University of Malawi, PMB 360, Chichiri Blantyre 3, Malawi

*Corresponding author: Tarkang EE, Department of Population and Behavioural Science, School of Public Health, University of Health and Allied Sciences, PMB 31, Ho, Volta Region, Ghana, Email: ebeyang1@yahoo.com

Citation: Tarkang EE, Gbogbo S, Lutala PM (2015) HIV/AIDS-Related Knowledge among Persons with Physical Disability in Cameroon: A Qualitative Study. J Aids Hiv Infec 1(2): 204. doi: 10.15744/2454499X.1.204

Received Date: September 21, 2015 Accepted Date: October 06, 2015 Published Date: October 08, 2015

\begin{abstract}
Introduction: The physically disabled have historically been excluded from HIV planning and programming largely due to perceptions that they are not sexually active. About 5.4\% of the Cameroon population lives with a disability. However, there is scarcity of literature on HIV/AIDS related knowledge among persons with disabilities, mainly because those who have been charged with HIV/AIDS control have not yet considered HIV/AIDS and how it affects people with disabilities. The objective of this study was to investigate the HIV/AIDS related knowledge among persons with physical disability in an urban town of Cameroon, in order to ascertain if this vulnerable population is also a key population in relation to the HIV epidemic.

Methods: The qualitative study from which this paper is based, used semi-structured in-depth interviews, conducted with a purposive sample of ten ( 5 male and 5 female) persons with physical disability, aged 18 years and above, in April 2015.

Results: The findings indicated that persons with physical disability perceived themselves to have low levels of knowledge regarding HIV/AIDS. However, they manifested accurate knowledge regarding HIV transmission and prevention.

Conclusion: It is therefore recommended that there should be educational programmes in HIV/AIDS, targeted specifically at persons with physical disability. Pertinent information on the ways HIV is not transmitted should be emphasised in all sexuality learning materials. All possible sources of misconception that could lead to stigmatisation and discrimination against people living with HIV (PLHIV) should be identified and clarified in such learning materials. It is also recommended that persons with physical disability who feel that they do not have sufficient knowledge about HIV/AIDS be formally informed about the disease.
\end{abstract}

Keywords: Cameroon; HIV/AIDS-related knowledge; Persons with physical disability; Urban town

\section{Introduction}

HIV/AIDS pandemic remains a major public health concern in sub-Saharan Africa (SSA), particularly in Cameroon, where more than 610000 people are living with the virus. Substantial variations in the burden of HIV/AIDS exist among the 10 regions of Cameroon, with the Southwest region ranking third, with a prevalence of $5.7 \%$ [1].

According to the recent world report on disability, around $15 \%$ of the world population lives with a disability and $80 \%$ of persons with disabilities (PWDs) live in developing countries [2,3]. They represent one of the largest and most underserved populations, and have an unmet need for health and HIV services in order to protect themselves.

Disability is often perceived negatively perhaps due to ignorance and some prevailing socio-cultural beliefs as well as economic factors. Persons with disabilities experience risk factors associated with acquiring HIV, which are varied and could be in the form of violation of human rights, poverty, stigma, discrimination and exclusion. Disability is closely associated with poverty and is also a barrier to education, employment, access to public services including health care and information and resources to facilitate safe sex, and social protection [4]. In most cases, disability has been addressed through charitable approaches without recognition of the rights and participation of persons with disabilities, like other citizens. 
Despite policy commitments at the international and national levels to improve the lot of PWDs, it appears the reality on the ground is that these commitments have not been translated into action. Furthermore, PWDs may be perceived negatively by society and accordingly treated inhumanly.

Persons with disabilities have been identified as one of the groups vulnerable to HIV due to several challenges posed by their disabilities. However, they have largely been ignored as part of HIV prevention programmes, and information is not being accessible. A lack of such information means that they do not receive adequate and life-saving information about the virus, its mode of transmission and prevention, and how to stay uninfected or how to care for others with infected with the virus.

The estimated HIV/AIDS prevalence rate in Cameroon is 5.3\% [5]. Here also, about 90\% of HIV transmission occurs through heterosexual intercourse [6]. About 5.4\% of the Cameroon population lives with a disability [7]. However, there is scarcity of literature on HIV/AIDS and people with disabilities in Cameroon. This is mainly because those who have been charged with HIV/AIDS control have not yet considered HIV/AIDS and how it affects people with disabilities. Despite growing recognition of the HIV prevention needs of people with disabilities (PWDs), there is a dearth of evidence related to experiences of PWDs in Cameroon [8]. In Cameroon, no official statistics exist on HIV/AIDS-related knowledge among PWDs. For the fight against HIV/ AIDS to succeed, policy makers and organisations must pay due attention to the plight of people with disabilities. Knowledge of HIV/AIDS plays a key role as a predictor of HIV risk behaviour. Accurate knowledge about HIV transmission and prevention is the gateway to behavioural change. Studies have demonstrated that HIV/AIDS knowledge is associated with condom use. Low level of knowledge about transmission and prevention of HIV/AIDS among adolescents is a predictor of non-use or inconsistent use of condoms [9].

Therefore, the proportions of disabled people who have comprehensive knowledge about HIV/AIDS are not known; the information hardly exists. With this scarcity of information, this study was conducted to investigate the HIV/AIDS-related knowledge among persons with physical disability in Kumba urban town of Cameroon.

\section{Methods}

This study used the qualitative research design, which is aimed at describing social phenomena and behaviours using rich contextual data that emphasise the subjective experiences of social actors. In-depth interviews provide a flexible tool for collecting narrative data describing interviewees' perspectives. The value of qualitative perspective has gained favour in social and behavioural health research, and in HIV/AIDS research in particular, where many of the social phenomena being studied are personal, intensively private and sometimes illicit [10].

Qualitative research methods are known to be appropriate and effective when little or nothing is known about the situation, as they do not require a predictive statement and therefore seek the answers to open questions $[11,12]$. Qualitative methods are also an effective tool when the target group are vulnerable, as is inevitably so, when focusing on PWDs.

Kumba, where this study was conducted, is an urban municipal area in the Southwest region of Cameroon, with a total population of approximately 166,000 inhabitants [13]. The Republic of Cameroon is divided into 10 regions. The North West and South West regions are predominantly English speaking while the other eight regions are predominantly French speaking. The Southwest region where this study was conducted has an HIV/AIDS prevalence of 5.7\%, which is above the Cameroon national prevalence $[1,14]$.

In this study we examined the HIV/AIDS-related knowledge of persons with physical disability, in their natural settings [15]. Participants for in-depth interviews were selected purposively through the Associations for persons with disabilities, resulting in a snowball sampling effect, resulting in 10 ( 5 male and 5 female) persons with physical disability for face-to-face semi-structured in-depth interviews.

This technique is often used when the researcher has specific requirements for the sample and picks a subject who meets these strict criteria [15]. To qualify for the study, participants had to be at least 18 years old and having physical disability. Data were considered saturated when no more new information were obtained [16].

Interviews were conducted with the aid of an interview checklist and included probes for further questioning [15], covering questions on HIV/AIDS-related knowledge. The interviews were conducted and audio-taped in Kumba by the first author, and sessions lasted about thirty minutes, and the audio-recordings were transcribed verbatim. To ensure accuracy, the transcriptions were cross-checked for inter-rater reliability by the first author who is a specialist in HIV research [17]. Quotes were edited for ease of reading but were not substantially altered. The quotations cited in this paper best represent the range of experiences and perceptions voiced around key themes. A theme was then defined as a "common thread that runs through the data" [18]. To maintain anonymity, these quotes are identified by gender and age. The transcripts were then reviewed to confirm the findings until saturation was reached, and quotes that best illustrate common theme, identified [19]. To assure quality of the data, the checklist was piloted with two physically disabled persons. Subsequently, some modifications were incorporated in the research instrument. 
Participants were given verbal and written information about the study and signed an informed consent form before being interviewed. No personal or identifying information was retained within transcripts. All interviewees participated on a voluntary basis and no financial incentives were provided. Ethical clearance for this study was obtained from the research and ethics committee of the faculty of philosophy, religious and social studies of the Cameroon Christian University (CCU). Permission to conduct the current research was obtained from research and ethics committee of the HIV/AIDS Prevention Research Network, Cameroon (HIVPREC) and from the Ministry of Social Affairs, Cameroon.

Past studies informed the development of the topic guide for the semi-structured in-depth interviews [20].

\section{Results}

Knowledge in this study refers specifically to issues relating to HIV/AIDS, including modes of transmission and preventive measures. Knowledge differs from simple awareness and is highly differential and multifaceted. Knowledge of the mode of transmission of HIV/AIDS and knowledge of protection against HIV/AIDS are articulated through the practice of safer sex and true knowledge on the issues of transmission and prevention.

\section{Perceived Level of HIV/AIDS-related knowledge}

The researchers wished to determine the knowledge level of the participants regarding HIV/AIDS in order to identify any gaps in their knowledge regarding HIV/AIDS. The participants indicated that their knowledge levels regarding HIV/AIDS are low according to the following participants. These responses are participants' personal opinions, but the actual measures of their knowledge might be different:

"Even though we might not have accurate knowledge about HIV, the little knowledge that we have, we pass it on to other PWDs so that we can protect ourselves from the disease" (Male, 45 years).

"We don't have much knowledge regarding HIV/AIDS, but those of us who have knowledge, try to educate the others" (Female, 35 years).

\section{Knowledge of transmission of HIV}

Considering how HIV is spread, there is a high level of knowledge among the participants that it is mostly spread through having sexual intercourse with an infected person. Other modes of HIV transmission are also well known to the participants. For example, unsafe blood transfusion and sharing sharp objects, according to the following quotes:

"HIV cannot be transmitted by drinking water from the same cup as an infected person" (male; 45 years).

"I don't believe that one can contract HIV by using the same toilet pot as an infected person because we know that there must be blood contact before transmission can occur" (female; 37 years).

"What we know is that HIV can be transmitted through unprotected sexual intercourse, through blood transfusion, from the mother to her baby during child birth and breast feeding, and by sharing injection needles and sharp objects with an infected person" (male; 45 years).

"If you have sex without using condoms, you will contract HIV" (female; 26 years).

\section{Knowledge of prevention of HIV}

People's awareness about how to avoid HIV enables effective execution of behaviour change programmes and strategies. Persons with physical disability who lack knowledge on the effectiveness of condom use to prevent HIV transmission, would less likely use them. Participants in this study exhibited accurate knowledge regarding prevention of HIV transmission, according to the following excerpts:

"To prevent HIV infection, you must accept Jesus Christ as your personal savior and remain faithful to God until you get married" (Male, 45 years).

"The church doctrine teaches us to protect ourselves from being infected with HIV. Correct use of condoms can prevent sexual transmission of HIV. However, than to use condoms, it is better to abstain from sex if you are not married, or to remain faithful to your partner if you are married. If you are single, you and your partner must do an HIV test before you get married" (female; 35 years).

"If you remain faithful to one sexual partner, you will prevent HIV infection" (female; 31 years).

"The best way to prevent HIV infection is to abstain from sexual intercourse until you get married" (male; 41 years) 


\section{Discussions}

Knowledge about HIV/AIDS can be assessed with respect to at least modes of HIV transmission, knowledge about HIV/AIDS prevention, and misconception about modes of HIV transmission. HIV is transmitted from one person to another mainly through heterosexual intercourse which accounts for above $90 \%$ of all infections [21]. HIV infection can also be transmitted from mother to child during pregnancy, during child birth and from breast feeding. Other modes of HIV transmission are through infected blood, blood products, donated organs or bone graft and tissues, common use of needles or other sharp objects [22]. With respect to AIDS prevention, most programmes focus prevention messages and efforts on three important aspects of behaviour change: delaying sexual debut for young persons (abstinence), limiting the number of sexual partners or staying with one faithful partner, and condom use $[22,23]$.

Participants in this study exhibited accurate knowledge regarding HIV transmission and prevention, despite the fact that they indicated their knowledge levels to be low. They were aware of abstinence as a major HIV prevention strategy. Use of condoms was highly reported, as well as being faithful to one sexual partner.

The acknowledgement of not having sufficient knowledge on HIV/AIDS by the participants could serve as a trigger for attending more formal programmes in sexuality education and on HIV/AIDS.

Of the three major modes of transmission, and seen within the parameters set by the contents of most information on HIV/ AIDS, sexual transmission may overshadow other modes of transmission of HIV/AIDS. Sexuality education should, in addition to emphasising safer sexual practices, also pertinently indicate the danger of any substance abuse and especially the danger of using contaminated injection needles.

People's health seeking behaviours to a large extent depend upon their understanding and interpretation of the causes of illness, in this regard, the causes of HIV/AIDS. True knowledge and understanding of HIV/AIDS is a necessary condition for behavioural change, although it is not per se the only condition [24]. Persons with physical disability with true knowledge on the mode of transmission of HIV/AIDS will have correct perceptions and attitudes regarding the disease, and will engage in safer sexual practices.

Full knowledge of the options available to persons with physical disability for the prevention of HIV/AIDS infection, from abstinence to safe sex, is important for empowering them, influencing the choices they make about sex, and preventing new HIV infections. Abstinence programmes focus exclusively on abstaining from sexual activity until marriage. Participants in this study mentioned sexual abstinence as a way of preventing HIV transmission. However, abstinence requires strong motivation, selfcontrol and commitment.

Even though participants in this study are aware of the effectiveness of condom use to prevent the sexual transmission of HIV, they might not know how to use them correctly, which could put them at risk of contracting HIV/AIDS. In addition, the perceived benefit of condom use to prevent HIV transmission might be overruled by perceived barriers to condom use, especially cost and unnaturalness of the device. This might determine whether or not a person with physical disability would actually use a condom to prevent HIV transmission. Sexuality education for persons with physical disability should emphasise the importance of correct and consistent use of condoms, especially during casual sexual encounters or when one's status, or that of one's partner is questionable or unknown.

Adolescents and adults with physical disability are more likely to be excluded from sex education programmes than other people. Knowledge level regarding HIV among persons with physical disability is perceived to be generally low, due in part to difficulties in accessing any kind of HIV education or prevention services. However, participants in this study exhibited accurate knowledge regarding HIV transmission, prevention and misconceptions.

\section{Conclusion}

Persons with physical disability in this study exhibited accurate knowledge regarding HIV transmission and prevention. They however, estimated their levels of knowledge regarding HIV/AIDS to be low. This calls for more formal programmes in sexuality education and HIV/AIDS in general, targeted at persons with physical disability.

\section{Recommendations}

In the light of the findings of this study, it is therefore recommended that in HIV/AIDS programmes there should be educational programmes targeted specifically at persons with physical disability, and organisations having such programmes should reach more disabled people with updated information about HIV/AIDS. Pertinent information on the ways HIV is not transmitted should be emphasised in all sexuality learning material. All possible sources of misconception that could lead to stigmatisation and discrimination against people living with HIV (PLHIV) should be identified and clarified in such learning materials. 
It is recommended that persons with physical disability who feel that they do not have sufficient knowledge about HIV/AIDS be formally informed about the disease. Formal estimation of the knowledge levels of persons with physical disability should be conducted from time to time. Persons with physical disability should also be updated on all changes in incidence statistics relating to HIV/AIDS as well as changes in the mutation of the virus. Programme providers need to guard against the idea that knowledge will necessarily result in expected behaviours. It is recommended that the implications of all aspects of both the disease and the causative virus be clearly explained to persons with physical, and where possible, an interactive presentation of information should be provided.

Persons with physical disability should be pertinently informed about the danger of transmission via blood. The focus on blood transfusion should be relayed to blood from epistaxis and open wounds often encountered in sports and road injuries. Sexuality education and health education on HIV/AIDS should include practical information and exercises on assisting persons who bled without endangering oneself, such as using surgical gloves, plastic shopping bags or any other watertight material. Moreover, policy frameworks should be more focused to guide and increase the access of the physically disabled to HIV/AIDS information and control services.

\section{Limitations}

Firstly, there is a chance of desirability bias, as participants may have responded to what they believe the interviewer wanted to hear and not an accurate representation of their opinions, perceptions and experiences. Nonetheless, being mindful of this, the author is a specialist in HIV research and he was not bias in the way he asked questions to the participants.

Secondly, the use of purposive sample could be a limitation because the results of the study cannot be generalised to the larger population of persons with disability. Reaching people through Associations of persons with physical disability means that participants are likely to be members of the Associations and therefore more likely to be active in the community. The researcher attempted to organise interviews through the Ministry of Social Affairs, with the aim of a more representative sample who may or may not be members of the disabled Associations. However, due to poor weather, timing, etc., all attempts failed. This again highlights the challenges in reaching the most vulnerable hard to reach population of persons with physical disability. Nonetheless, this qualitative assessment was able to provide context and information on a topic where limited data is available.

\section{References}

1. Cameroon Demographic and Health Survey and Multiple Indicators Cluster Surveys (2011) Cameroon.

2. WHO (2011) World Report on Disability. Geneva, Switzerland: WHO.

3. UNAIDS (2014) People with disabilities, The gap report. Geneva, Switzerland: UNAIDS.

4. Groce NE (2004) The Yale University/World Bank Global survey on HIV/AIDS and disability. New Haven, Yale University.

5. UNAIDS (2010) Report on the global AIDS epidemic. Geneva, Switzerland: UNAIDS.

6. Fonjong L (2001) Fostering women's participation in development through Non-governmental efforts in Cameroon. Geographical J Royal Geographical Soci 167: 223-34.

7. Tchamgoue H, Nantchouang A (2012) Chapter 16: Handicap. In INS Institut National de la Statistique et ICF. International. Enquête Démographique et de Santé et à Indicateurs Multiples du Cameroun 2011. Calverton, Maryland, USA: INS et ICF International.

8. Cockburn L, Cleaver S, Benuh E (2014) The prevalence of impairments and disabilities in the Northwest region (Cameroon). Health Sci Dis 15: 1-7.

9. Osborn CY, Paasche-Orlow MK, Davis TC, Wolf MS (2007) Health literacy: An overlooked factor in understanding HIV health disparities. Am J Prev Med 33: 374-8.

10. Silverman D (2006) Interpreting qualitative data: methods for analyzing talk, text and interaction $3^{\text {rd }}$ ed. London: Sage Publications.

11. Stone E (1999) Disability and Development. The Disability Press, Leeds.

12. Roux W (2002) The challenges of change. Early childhood development: Practice and reflections. No 15. Bernard van Lear Foundation, Netherlands.

13. Bureau Central des Recensement et des Etudes de Population, Livre "Rapport de Presentation (2010) Cameroon.

14. The Pointer (2012).

15. Bowling A (2002) Research methods in health: investigating health and health services. $2^{\text {nd }}$ ed. Open University Press, Buckingham.

16. Glaser BG, Strauss AL (1967) The discovery of grounded theory: strategies for qualitative research. Aldine Transaction: California, CA.

17. Pitchforth E, van Teijlingen E (2005) International public health research involving interpreters: a case study from Bangladesh. BMC Public Health 5: 71.

18. Richards L, Morse JM (2007) User's Guide to Qualitative Methods. Thousand Oaks, CA: Sage Publications Inc.

19. Strauss A, Corbin J (1998) Basics of Qualitative Research: Techniques and Procedures for Developing Grounded Theory. Thousand Oaks, CA, Sage Publications.

20. Kurth ACM, Moore A (2005) Formative research for computer counselling intervention to support antiretroviral adherence. A State of the Science Meeting on Intervention Research to Improve Anti-Retroviral Adherence. Yale University.

21. Barnett T, Whiteside A (2006) AIDS in Twenty First Century, Disease and Globalization. Palgrave Macmillan: 175 Fifth Avenue, New York, ISBN: 1403997683.

22. TACAIDS, NBS, ORC Macro. Tanzania HIV/AIDS Indicator Survey 2003-04. (2005) Calveton Maryland, United State of America (USA). 
23. Tanzania Commission for TAIDS (TACAIDS), Zanzibar AIDS Commission (ZAC), National Bureau of Statistics (NBS), Office of the Chief Government Statistician (OCGS), ICF International. Tanzania HIV/AIDS and Malaria Indicator Survey 2011-12. 2013. Dar es Salaam, Tanzania: TACAIDS, ZAC, NBS, OCGS, and ICF International.

24. Uwalaka E, Matsuo H (2002) Impact of knowledge, attitudes and beliefs about AIDS on sexual behaviour change among college students in Nigeria: the case of the University of Nigeria, Nsukka. West African Review. 3: 1525-4488.

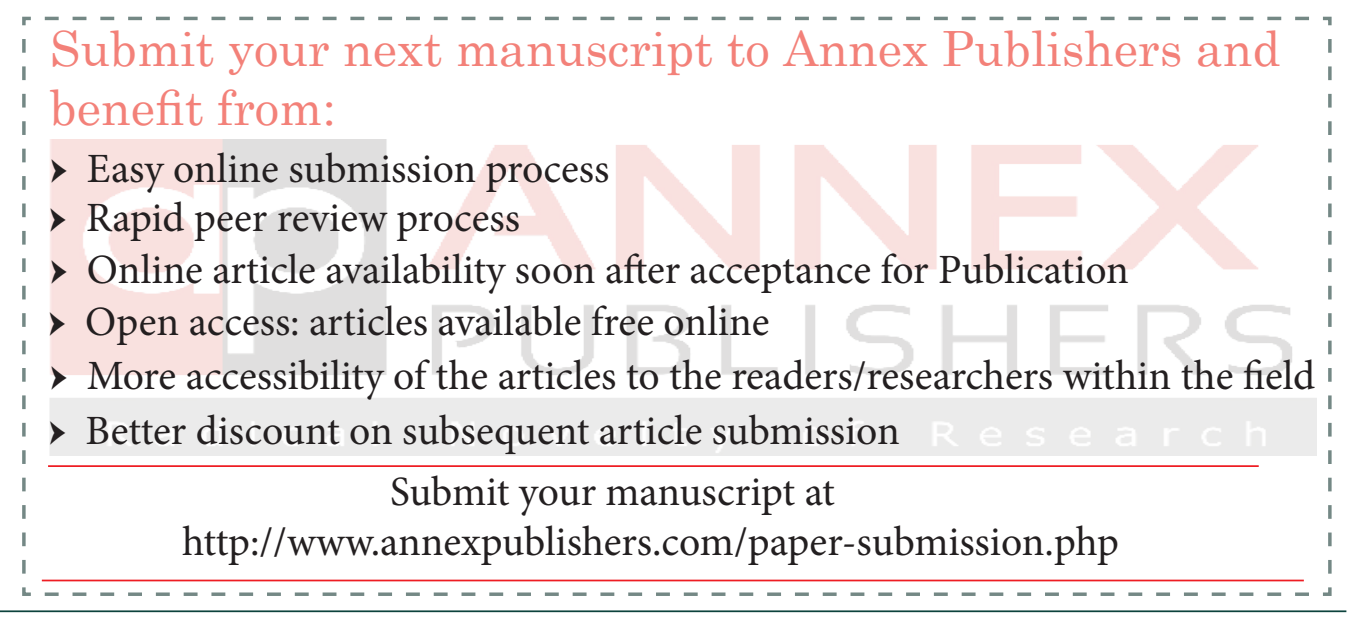

